\title{
Histiocitosis Hemofagocítica y Aplasia Medular en Fiebre Tifoidea
}

\author{
Drs. Verónica Valdés L.2, Dra. Marcela Ferrés G.2, \\ Hơmán Tahoada L. 1-3

\section{Hemophagocytic Histiocytosis and Aplastic Anemia in Tyhoid Fever}

\begin{abstract}
Two cases of typhoid fever in chuldren aged under two years are reported, both presenting a severe pancytopenia associated with bone-marrow (and probably also hepatic and splenic) hemophagoeytic histiocytosis. In one of thetr this was accompanied by a serious bone-marrow aplasia. Both pathologic findings rexponded promptly to treatment witl cloramphenicol or cotrinoxazol associated to prednisone. We cannot rule out the possibility that the hematologic recovery was unrelated to sterords.

Pathogenic mechanisms by means of wich salmolella typhi mighi produee these severe complications are discussed. We stress the fack that in the bibliography revised, only one reference was found to histiocytic medulary reticulosis and nonc ralated to bonemarrow aplasia produced by typhoid fever.
\end{abstract}

La fiebre tifoidea se presenta con frecuencia asociada a neutropenia y/o a anemia de poca intensidad, más raramente a trombocitopenia; excepcionalmente se puede llegar a una pancitopenia importante. En el último año tuvimos la oportunidad de estudiar dos casos de fiebre tifoidea en niños menores de dos años que presentaron pancitopenia severa asociadta a sindrome hemofagocítico, uno de ellos con aplasia medular, lo que motiva la presente comunicación.

\section{Casos Clínicos}

\section{Caso 1.}

C.L.B. (Obs. 250338). Ingresa por 20 dias con

1 Presentado à Congreso de Becarios - Concepción Novicmbre 1982.

2 Becarios pediátricos, Hospital Sótero del Río, S.S.M.S.O.

${ }^{7}$ Médico hematólogo. Servicio Pediatría Hosp. Sótero del Río S.S.M.S.O.

Docente Departamento Pedjatría U. Católica. fiebre alta, diarrea, tos y edema progresiwos. Durante su enfermedad fue tratado con Penicilina durante 4 días. En el examen de ingreso se describe como un niño conciente, febril, palidez de piel y mucosas, sin petequias ni adenopatías. Dermatitis seborreica del cuero cabclludo, labios erosionados y lesión costrosa de una mejilla.

Disminución del murmul]o vesicular en la base pulmonar derecha. Abdomen globuloso, hígado $\mathrm{y}$ bazo, ambos $6 \mathrm{~cm}$., bajo el reborde costal duros. Matidez desplazable.

Edema de manos y pjernas hasta la rodilla.

Hemograma: Hcto 18\%, 6.700 leucocitos con 268 neutrófilos xnm ${ }^{3}$ y 25.000 plaquetas.

Protrombina $42 \%$, que sube a $86 \%$ después de Vit. $K$.

Proteinemia $5.9 \mathrm{~g} / \mathrm{dl}$. con $43.2 \%$ de albumina, $7.0 \%$ de $\propto 1,15.1 \%$ de $\propto 2,13.1 \%$ de $\beta$ y $21.6 \%$ de gama-..globulinas, bilirrubinemia y transaminasas normales; fosfatasas alcalinas 68 (UB), prueba de Coombs negativa: radiografías de tórax y cráneo normales. 
Mielograma de buena celularidad. Megacariocitos proporcionalmente disminuidos, con producción de plaquetas. Serie Granulocítica $65.0 \%$ : Eosinofilos 1.5\%; Linfocitos $9.0 \%$; Cels. Plasmáticas $0.0 \%$; Monocitos $5.0 \%$; Histiocitos $0.0 \%$. Serie Eritrocítica 19.5\%: Tendencia a la macrocitosis, con escasos megaloblastos policromáticos. Al recorrer el frotis se encuentran células plasmáticas, algunos monoblastos y promonocitos; e histiocitos con hemofagia de glóbulos rojos, eritroblastos, neutrófilos y plaquetas. 1 Histiocito multinucleado.

Por anemia, hematuria y deposiciones con sangre fresca se indicó transfusión de glóbulos rojos y concentrado de plaquetas. Se administró además Furoxona, pero siguió febrtl, de aspecto más grave y apareció poliuria. El resultado del mielograma en que habian histiocitos multinucleados y hemofagia, síndrome febril prolongado, hepatoesplenome. galia, dermatitis seborreica, anemia, trombocitopenia y neutropenia sugeria una histiocitosis X. Dada la gravedad del niño se inició tratamiento con Oncovin $0,5 \mathrm{mg}$. y Prednisona $2 \mathrm{mg} / \mathrm{Kg}$. Por sospecharse una infección sobreagregada se indicó también Penicilina y Trimetroprin-Sulfisoxasol.

Evolucionó favorablemente; el segundo Hemograma mostró Hematocito $44 \%$; Leucocitos 6.300 ; Neutrofilos $3.276 \mathrm{xmm}^{3}$; Plaquetas 150.000 . Luego se reciben los resultados de los hemocultivos con identificación de Salmonella Typhi, por lo que se suspendió Oncovin y prednisona y se completan 14 dias con Septrin, desapareciendo la fiebre, hepato-esplenomegalia $y$ pancitopenia.

\section{Caso 2.}

I.B.F. (Obs. 303677), 1 Año, 2 meses. Desnutrición Calórica y proteica grado I. Referida del Hospital de Curicó, donde estuvo 5 dias, con antecedente de Síndrome febril de 10 dias de evolución, palidez, astenia y compromiso del estado general. No recibió medicamentos antes de su hospitalización.

Palidez intensa de piel y mucosas, exantema eritematoso macular (rubeoliforme) de cara, tronco y extremidades; sin enantema, petequias ni adenopatías. Soplo sistólico cardíaco grado [V/VI, que desaparece luego de ser transfundido. Hígado a $3 \mathrm{cms}$. bajo el reborde costal. Examen neurológico normal. Al ingreso en Curicó el Hemograma tenía Heto, $11 \%$, Reticulocitos $0 \%$. Leucocitos $1.250 \times \mathrm{mm}^{3} ; 1$ Bac. 2 Seg. 97 Linfo. \%. Se transfundó antes de su traslado con el diagnóstico de aplasia medular.

Después de tomat cultivo de sangre y Liquido Céfalorraquídeo (LCR), se inició tratamiento con Penicilina, Cloxacilina y Gentamicina.
El examen citoquímico y cultivo de LCR fueron normales; Orina Normal; Coombs Negativo; Electroforesis de proteínas Normal; Hematocito $35 \%$, leucocitos $4.300 \mathrm{x} \mathrm{mm}^{3}$, neutrófilos $129 \times$ $\mathrm{mm}^{3}$ : plaquetas $40.000 \mathrm{x} \mathrm{mm}^{3}$ en sángre periférica, Mielograma con Celularidad pobre, algunos grumos de estroma; Megacariocitos escasos, con formación de plaquetas.

Serie granulocitica $2 \%$ (escasos promielo y mielocitos vacuolados), Eosinófilos $0.5 \%$; Lifocitós $73.0 \%$; Células plasmáticas $1.5 \%$; Monocitos $8.0 \%$; Histiocitos $2.0 \%$ : Serie eritrocitica $13.5 \%$ (Nomocítica). Frecuentes mono-histiocitos, histiocitos rodeados de linfocitos e histiocitos con hemofagia (de glóbulos rojos, eritroblastos, plaquetas, polimorfonucleares y linfocitos). En resumen se concluyó que había Itipoplasia medular global, con hemofagia activia y vaculación en los precursores granulocíticos. Histiocitosis reactiva.

Con el resultado del mielograma y por haber encontrado linfocitos hiperbasófilos y células en mitosis en sangre periférica, se pensó una aplasia medular secundaria a un cuadro viral, probablemente mononucleosis infecciosa, por lo que se inicia tratamiento con Prednisona $4 \mathrm{mg} / \mathrm{Kg} / \mathrm{dia}$.

Posteriormente llegaron los informes de hemocultivos positivos para Salmonella Typhi, y con el antecedente del caso antcrior, se planteó que la fiebre tifoidea era la causante de la aplasia medular. Se imició tratamiento con Cloramfenicol y suspendió progresivamente la prednisona al comprobarse una buena respuesta clínica $y$ hematológica (Hto. 36\%, aumento de los polimorfonucleares a $1.680 \times \mathrm{mm}^{3}$ y de las plaquetas a $300.000 \times \mathrm{mm}^{3}$ ). El mielograma de control reveló mediana celularidad, con algunos grumos de estroma, Megacariocitos presentes, con entrega del plaquetas. Serie Granulocítica: $22.5 \%$ (Promielocitos $2.0 \%$, mielocitos $2.5 \%$, metamielocitos $3.5 \%$, ba. ciliformes 7.0\%, Segmentados 6.5\%); Eosinofilos $1.0 \%$; Linfocitos: $38.0 \%$; Cels. plasmáticas: $00 \%$; Monocitos: $11.0 \%$; Histiocitos: $0.0 \%$. Serie etitrocítica $28.5 \%$. Al recorrer el frotis se encuentran histiocitos rodeados de eritroblastos (Células nodrizas). En resumen, se encuentra hipoplasia medular global, hiperplasia eritroide y monocítica relativa, e hipoplasia granulocítica franca.

No dudamos en recurrir al Cloramfenicol para tratar la tifoidea, ya que la aplasia exa producida por la gravedad de esta infección. La mejorîa hematologica rápida ratificó nuestra actitud de no temer al empleo de dicho antibiótico ante tifoideas graves con anemia, neutropenia yo trombocitopenia.

En el mielograma de control cabe destacar un cambio notable, pues en lugar de los histiocitos hemofagociticos iniciales, ahora se encuentran 
histiocitos que entregan nutrientes (ferritina $y$ ifactor estimulante de colonias? ) a los eritroblastos.

\section{DISCUSION}

Revisando las publicaciones pediátricas nacionales $^{1 \cdot 3}$ y extranjeras ${ }^{4-11}$ no hemos encontrado referencias explícitas a casos de fiebre tifoidea con las características de los presentados por nosotros. Autores nacionales ${ }^{12}$ que revisaron las salmonellosis en el lactante (paratifus B y tifoidea), destacaron la presencia de hepatomegalia (6 de 11 casos) y con menor frecuencia esplenomegalia (2 de 11 casos), pero no describieron alteraciones hematológicas significativas. Autores peruanos ${ }^{13}$ presentaron, en su experiencia sobre fiebre tifoidea en niños menores de 2 años ( 9 casos), dos pacientes con hepato-esplenomegalia importante $(6-5$ y 5

$4 \mathrm{~cm}$. respectivamente), uno con anemia intensa y trombopenia, el otro sólo con anemia, pero ninguno con neutropenia. En uno de ellos se pensó al ingreso en leucemia, a semejanza de nuestro caso 1, que parecía histiocitosis X. Estas observaciones son aleccionadoras y obligan a plantear la posibilidad de fiebre tifoidea en el lactante y niño menor con fiebre, gran hepato - esplenomegalia $y$ pancitopenia.

El segundo de nuestros casos tiene uri interés adicional, porque además de pancitopeniá severa, tenía hipoplasia medular importante, lo que hizo creer que se trataba de aplasia medular con infección secundaria a la neutropenia. Sin embargo nos llamó la atención, en el mielograma, que junto con granulocitopenia casi total se encontraron algunos megacariocitos con producción de plaquetas, existiendo además frecuentes histiocitos con hemofagia (de glóbulos rojos, eritroblastos, plaquetas $y$ neutrófilos). Esto nos indujo a plantear una histiocitosis reactiva o idiopática, y por encontrar en sangre periférica linfocitos hiperbasófilos y algunas células en mitosis pensamos en primer lugar en un sindrome hemofagocítico viral, por citomegalovirus (CMV) o virus de Ebstein-Barr, (EBV), que son, en ese orden, sus causas más frecuentes ${ }^{14-15}$. Más específicamente lo atribuíamos al virus EB, pués se ha relacionado con mayor frecuencia a aplasia medular rápidamente reversible con tratamiento córtico-esteroidal ${ }^{16}$. Resultó por lo tanto sorprendente el aislamiento, en el hemocultivo, de Salmonella Typhi, no tanto por la presencia de histiocitosis hemofagocítica, que ya habíamos encontrado en el mielograma de varios casos de tifoidea, sino por la aplasia medular que era para nosotros un hecho inédito en esta enfermedad.

Revisando exhaustivamente las publicaciones sólo encontramos una referencia de un autor
Sud-africano que comunica en una carta al Lancet $^{17}$ el hallazgo de reticulosis histiocitica medular (o sea, hemofagocitica por excelencia) en la fiebre tifoidea del adulto. Con respecto a aplasia medular sólo hemos encontrado relaciones marginales con infecciones por Salmonella Typhi, referidas más bien a neutropenia ${ }^{18}$. Entre las causas infecciosas de esta grave falla medular destacan el (o los) virus de la hepatitis, con menor frecuencia el virus EB y raramente el CMV, el varicela---zóster y el de la rubeola. Entre los agentes bacterianos se mencionan la tuberculosis y la brucelosis, $y$ entre los parasitarios la toxoplasmosis ${ }^{19 \cdot 22}$. No encontra. mos ninguna referencia a Salmonellosis o a fiebre tifoidea en especial, en cambio en la lista de las afecciones que pueden producir histiocitosis reactivas con hemofagia se encuentran la TBC, lepra, lúes, micosis, toxoplasmosis, salmonellosis, brucellosis, listeriosis e infecciones por virus (CMV, EBV, $y$ otros $)^{23}$. Nosotros la hemos encontrado en forma prominente en un caso de hepatitis, sin poderla atribuir a un virus en especial, pero al parecer no producida por el EBV ya que se trataba de una niña prepúber que no tenia un síndrome mononucleósico 24

Cabe aqui una última reflexión que pudiera tener implicaciones patogénicas. La mayoría de los agentes patógenos que producen histiocitosis hemofagocítica (y también la histiocitosis $\mathrm{x}$ o idiopática) están implicados como posibles causantes de aplasia medular. Especial relevancia nos parece que tienen los virus. Algunos producen aplasia medular de muy mal pronóstico, como es el caso de los de la hepatitis ${ }^{25}$. Otros, en especial el EBV, producen una aplasia intensa que se recupera rápidamente (en 4 a 10 días), al parecer en relación con el tratamiento corticoidal ${ }^{16}$. Este último hecho permite suponer la existencia de células supresoras de la hematopoyesis (linfocitos y/o macrófagos), to que no ha sido establecido fehacientemente. El virus podría actuar ya sea suprimiendo linfocitos $\mathrm{T}$ supresores (o inhibidores), lo que permitiría la expresión de linfocitos citotóxicos que pueden dañar a los precursores hematopoyéticos; o bien infectando o parasitando las células precursoras hernatopoyéticas modificando sus antígenos de membrana, haciéndolas susceptibles de ser agredidas por linfocitos citotóxicos que cumplirían así la misión inmunológica de climinar 10 "extraño" o "no propio"26-27.

A falta de evidencia directa podemos citar un trabajo reciente sobre histiocitosis $X$, en el que se encuentra una franca disminución de linfocitos $T$ supresores con presencia de linfocitos citotóxicos y un anticuerpc unido a los glóbulos rojos, que no se hacía evidente en la prueba de Coombs. Los finfocitos citotóxicos y/o o los anticuerpos unidos 
a las células hematopoyéticas explicarian la estimulación de los histiocitos que responden con proliferación y macrofagia activa (autofagia) ${ }^{28}$. Un trabajo publicado por nosotros con detección de leucoaglutininas apunta en este mismo senti$\mathrm{do}^{29}$. Por otra parte en histiocitocis reactivas se ha descrito un aumento de los receptores $\mathrm{Fc}, \mathrm{C} 3$ y de histocompatibilidad en los macrófagos, lo que contribuiría a su mayor reactividad funcional ${ }^{30}$. En la tuberculosis diseminada se encuentran granulomas en la médula ósea, que se acompafian de hipoplasia hematopoyética $y$ pancitopenia periférica con neutropenia severa. Se ha demostrado hiperesplcnia mediante la mejoría obtenida con la esplenectomia, pero además se ha puesto en evidencia la existencia de linfocitos $\mathrm{T}$ supresores que inhiben los cultivos de médula y que desaparecen con al tratamiento antituberculoso, mejorando la pancitopenia ${ }^{30-31}$

Experimentalmente se ha inducido en ratas in. fectadas con mycobacterium lepraemurium la aparición de macrófagos supresores que luego son reemplazados por linfocitos $T$ supresores detectables en la sangre periférica y en el bazo ${ }^{32}$. Esto permite suponer que lo mismo pudiese ocurrir en la fiebre tífoidea: El bacilo tífico está presente en la médula ósca $190 \%$ de mielocultivos positivos versus $40 \%$ en hemocultivos) ${ }^{33}$ : y produce formación de granulomas en hígado, bazo y médula lo que significa activación in situ de los macrófagos con aparición de un efecto supresor junto con aumento del poder bactericida local.

La secuencia de eventos a nivel de citología molecular seria la siguiente: Los polimorfonucleares neutrófilos estimulados por la infección movilizan sus enzimas lisosómicas hacia las vacuolas fagocíticas $y$ en parte las secretan. Entre estas últimas se eficuentra la lactoferrina, que es un potente quelante de Fe y que al unirse a la menbrana del neutrófilo contribuye a la activación del poder bactericida (generación de peróxido, superóxido y radical oxhidrilo activo ${ }^{34}$.

Por otra parte el complejo lactoferrina - Fe se une a los receptores específicos de los monocitos e histiocitos estimulando la endocitosis (secuestro de Fe a nival del sistema reticulo endotelial, principalmente en bazo e hígado). La unión lactoferrinareceptores activa la fosfolipasa de la membrana con lo que se libera ácido araquidónico iniciándose la síntesis de prostaglandina $E^{35}$. La Prostaglandina $E$ inhibe por una parte la síntesis, en el macrófago, del factor estimulante de colonias $(\mathrm{CSF}=$ colony stimulating factor $)$ responsable de la proliferación de las colonias granulociticas, mientras por otra estimula a los linfocitos que inician su proliferación y la síntesis y entrega de linfoquinas por los linfocitos I. Entre las linfoquj- nas mencionaremos los peptidos quimiotácticos (para monocitos, eosinófilos...), el factor inmovilizador del macrófago (MIF), el factor activador del macrófago (MAF), el factor de transferencia (TF), el factor mitogénico (MF), la linfotoxina (LT) y la interferona gama o inmune (IN). Esta última es una glicoproteina que interfiere, en el ribosoma, la síntesis de ácido desoxiribonucleico (DNA), ribonucleico (RNA) y ciertas proteínas (entre ellas enzimas), impidiendo así la multiplicación viral pero inlubiendo también la hematopoyesis. El interferon además es responsable del aumento de la fagocitosis de los macrófagos, de la citotoxicidad mediada por los linfocitos $T y$ por los linfocitos citotóxicos naturales (natural killer), de la libera. ción de histamina del basófilo mediada por IgE y de la aparición de linfocitos $T$ supresores al aumentar la expresión de los receptores Fc gama (para IgG) ${ }^{36}$. Estos linfocitos supresores pueden participar en la inhibición de la hematopoyesis y ser asi responsables de las citopenias que acompañan a las infecciones virales y en ocasiones también a ciertas infecciones bacterianas.

Quedaria así explicado que se produzca por un lado acumulación y activación de los macrófagos (es decir, histiocitosis) y por otro lado mayor o menot inhibición medular (es decir, hipoplasia).

La hemofagia encontrada en forma prominente en nuestros casos no tendría una explicación tan evidente. Fn un caso anterior efectuamos pruebas de Coombs diferenciadas - anti IgG, anti IgM y anti $\mathrm{C} 3$ - siendo todas ellas negativas. Puede postularse sin embargo que igual que en la histiocitosis $X$, es posible que exista un anticuerpo opsonifican. te de baja concentración pero muy activo, que al unirse a la superficie de las células sanguineas lleve a su reconocimiento y fagocitosis por los macrófágos ya activados por la infección. Avalan esta hipótesis la demostración de casos de anemia hemolítica inmune con prueba de Coombs negati$\mathrm{va}^{37-38}$, y la detección de un aumento de las IgG en la membrana de las plaquetas en casos de septicemias en adultos y en recién nacidos ${ }^{39-40}$.

Habriamos establecido así un puente de unión entre la histiocitosis hemofagocítica $y$ la aplasia medular. La hemofagia que encontramos en la médula de nuestros casos de tifoidea nos permite suponer una mayor participación en ella de los macrófagos del bazo y del higado, aumentados de tamaño y comprometidos en la eliminación del bacilo tífico. Así se puede explicar la pancitopenia del primer caso, ya que no existía compromiso cuantitativo de la hematopoyésis medular. En el segundo caso en cambio no había visceromegalia importante, predominando una aplasia medular severa. En ambos la situación se corrigió rápidamente con el tratamiento antítífico. No podemos 
afirmar que el uso de corticoides (asociado Vincristina en un caso) haya contribuido significativamente a la mejoría hematológica mediante la inactivación de linfocitos y/o macrófagos supresores, o inhibiendo la hemofagia por estabilización de la membrana celular. La misma duda proponen los autores que han revisado el problema de la aplasia medular producida por la mononucleosis infeccio$\mathrm{sa}^{16}$, que es similar a la que se presenta en la tifoidea.

\section{RESUMEN}

Se comunican 2 casos de fiebre tifoidea en niños menores de 2 affos que presentaron pancitopenia severa asociada a histiocitosis hemofagocítica medulat, y seguramente también hepática $\mathrm{y}$ esplénica. En uno de ellos se acompañó de aplasia medular grave. Ambas manifestaciones respondieron rápidamente al tratamiento con Cloramfenicol - Cotrimoxazol, asociado a Prednisona. No se puede concluir que la Prednisona haya contribuido significativamente a la mejoria hematológica.

Se discuten los mecanismos patogénicos por los que el bacilo tífico puede producir estas graves complicaciones. Destacamos que en la revisión bibliográfica encontramos sólo una referencia de reticulosis histiocítica medular y ninguna en relación a aplasia medular producidas por la fiebre tifoidea.

Como conclusión final podemos afirmar que en la tifoidea grave complicada de aplasia medular 0 neutropenia severa no está contraindicado el empleo de Cloramfenicol.

\section{REFERENCIAS}

1 Meneghello, J.J, y Cols.: Análisis clínico-estadístico de 159 casos de fiebre tifoidea. Rev. Child. Ped. 10: 767,1968 .

${ }^{2}$ Bancalari, A.: Banfi, A.: Fiebre tifoídea: Experiencia en 831 casos Pediátricos. Rev. Med. Chil. 106: 609. 1978.

${ }^{3}$ Espinoza, L.M.N.; Rubio, S.: y Cols. Fiebre tifoidea complicaciones en 782 niños hospitalizados. Rev. Chil. Ped. 52: 113, 1981.

4 Hornick, R.B.: y Cols. Typhoid fever: Pathogenesis and inmunologic control. N. Eng. J. Med. 283: 686 y 739,1970

5 Hornick, R.B.; Greismm, S.: On the pathogenesis of typhoid fever. Arch. Int. Med. 138: 357, 1978.

6 Buthler, F. y Cols.: Typhoid fever. Arch. Intern. Med. 138: $407,1978$.

7 Foote, S.C.; Hook, E.W.: Salmonella species: Including typhoid fever. En "Principles and practice of infectious diseases" Mandell, G.L. y Cols.; New York, John Willey and Sons, 1979, Cap. 179, pag. 1730.

8 Dan, M, y Cols.: Typhoid hepatitis with inmunoglobulins and complement deposits in bile canaliculi. Arch. Inter. Med. 142:148, 1982

9 Nasralah, S.M.; Nassoo, V.H.: Enteric fever. Am. J. Gastroenterol. 69:63, 1978.
10 Congy, F.; y Cols.: Trombocitopenic au course de la fiévre typhoide. Nouv. Press. Med. 6: 3551, 1977.

11 Woutier, J.L.: Mécanisme de la trombopénie au cours de la fievre typhoide. Nouv. Press. Med. 7: 667, 1978.

12 Wisnis, S.; Norero, $C_{\text {.; }}$ Schilling, E.: Salmonellosis en el lactante. Rev. Chil. Ped. 39: 302, 1968.

13 Palacios, P.G.; y Cols.: La fiebre tifoidea en el riño menor de dos años. Bol. Med. Hosp. Inf. Mex, 38: $473,1981$.

14 Resdall, R.J.; y Cols.: Virus-associated hemophagocytic syndrome. A berign hystiocyte proliferation distinct from malignant histiocy tosis. Cancer 44: 993, 1979.

Is Wilson, E.R.; y CoLn: Fatal Epstein-Bari virus associated hemophagocytic syndrome. J. Pediat. 98: $260,1981$.

16 Lazorus, K.H.; Boehner, R.L.: Aplastic anemia complicating infectious mononucleosis. Pediatrics 67: 907, 1981 .

17 Fernóndez - Costa, F.; Eintracht, l.: Histiocytic me dulary reticulosis. Lancet 2: 204, 1979.

18 Weetman, R.M,; Boxer, L.A.: Childhood neutropenia. Ped. Clin. N.A. 27: 361, 1980.

19 lipton, J.M.; Nathan, D.G.; Aplastic and hipoplastic anemia. Ped. Clin. N.A. 27: 217, 1980.

20 Alter, B.P.: Bone-martow failute in children. Pediat. Ann. 8: 44, 1979 .

21 Gale, R.P.: Champlin, R.E.; Feig, S.A.; Fetchen, 1.H. (UCLA Conf.) Aplastic Anemia: Biology and treatment. Ann. Intern. Med. 95: 477, 1981.

22 Camitta, B.M.; y Cols.: Aplastic Anemia: Pathogenesis, diagnosis, treatment, and prognosis. N. Eng. J. Med. 306: 645 y 712,1982 .

23 Goopman, J.E.; Golde, D.B.: The histiocitic disorders: A pathophysiologic analysis. Ann. Intern. Med. 94: 95,1981 .

24 .Dello Magiora, M.E.; Taboadn, H.; Donoso. J.M.: Alteraciones hematológicas en la hepatitis viral. Congreso Chil. de Ped. 1981 Stgo.

25 Hagler, L.; $y$ Cols.: Aplastic anemia following viral hepatitis. Report of two fatal cases and literature revew. Medicine 54: $139,1975$.

26 Appelbaum, F.R.; Fefer, A.: The pathogenesis of aplastic anemia. Seminars Hematol. 18: 241, 1981.

27 Bagty, C.E.; y Cols.: Prednisone responsive aplastic anemia: A mecanism of glucocorticoid action. Blood 54: 322,1979 .

28 Ashord, M.E.; y Cots. Histiocytosis X: Demostration of abnormal inmunity, $\mathbf{T}-\mathrm{Cell}$ histamine $\mathbf{H}_{2}$-receptor deficiency, and successful treatment with thymjc extract. N. Eng. J. Med. 304: 146, 1981.

29 Taboada, $H, ;$ y Cots. Histiocitosis X. Rev. Chil. Ped. 46: 239,1975 .

30 Editoriol: Mycobacterial infection and leucopenia. Lancet 2: 184, 1981.

31 Babgy, G.C.: Gilbert. D.N.: Suppression of granulopoiesis by $\mathbf{T}$-limphocytes in two patients with disseminated mycobacterial infection. Ann. Int. Med. 94 ; 478,1981

32 Bullock W.E.; $y$ Cols.: The evaluation of inmunosuppressive cell population in experimental mycobacterial infection. J. Inmunol. 120: 1709, 1978

33 Gilman, R.H.; y Cols.: Relative efficacy of blood, urine, rectal swab, bone-marrow, and rose-spot cultures for recovery of salmonella typhi in typhoid fever Lancet 1: 1211, 1975

${ }^{34}$ Boxer, L.A.; y Cols.: Lactoferrin deficiency associated with altered granulocytic function. N. Eng. J. Med. 307: 404, 1982. 
35 Phitip. M.A. y Cols.: Failure of chronic-granulocytic-leukenia leucocytes to release an inhibitor of granulopoicsis. Lancet 1: 866, 1981.

36 Stiehm. R.: y Cols.: (UCLA Conference) Interferon: inmunobiology and clinical significance, Ann. Intern. Med. 96: 80, 1982 .

37 Hidge, Y.M, y Cois.: Reticulocitopenia and abcense of red cell antibodies in inmune haemolytic anemia. Br. Med. J. 2: 1444, 1977.
38 Conley, C.L.; y Cols.: Autoimmune hemolytic anemia with reticulocytopenia and erytroid marrow. N. Eng. J. Md. 306: 281, 1982.

39 Kelton, J.G.; y Cols.: Llevated platelet associated lgG in the thrombocytopenia of septicemia. N. Tng. $\mathrm{s}$. Med. $760,1979$.

40 Tate, D.: y Cols.: Imnume thrombocy topenia in severe reonatal infections. J. Pediatr. 98:449, 1981. 